\title{
DNA Methylation-Dependent Translational Control of Glutamate Transporters in Cultured Radial Glia Cells
}

\section{Ada G Rodríguez-Campuzano}

Centro de Investigación y de Estudios Avanzados del IPN

Luisa C. Hernández-Kelly

Centro de Investigación y de Estudios Avanzados del IPN

Arturo Ortega ( $\sim$ arortega@cinvestav.mx)

Centro de Investigación y de Estudios Avanzados del IPN https://orcid.org/0000-0002-9594-8114

\section{Research Article}

Keywords: DNA methylation, Glutamate transporters, radial glia, transcriptional control

Posted Date: August 25th, 2021

DOI: https://doi.org/10.21203/rs.3.rs-824210/v1

License: (c) (i) This work is licensed under a Creative Commons Attribution 4.0 International License.

Read Full License 


\section{Abstract}

Exposure to xenobiotics has a significant impact in brain physiology, that could be liked to an excitotoxic processes induced by a massive release of the main excitatory neurotransmitter, L-

glutamate. Overstimulation of post-synaptic and extra-synaptic glutamate receptors leads to a disturbance of intracellular calcium homeostasis that is critically involved in neuronal death. Hence, glutamate extracellular levels are tightly regulated through its uptake by glial glutamate transporters. It has been observed that glutamate regulates its own removal, both in the short-time frame via a transporter-mediated decrease in the uptake, and in the long-term through the transcriptional control of its gene expression, a process mediated by glutamate receptors that involves the $\mathrm{Ca}^{2+} /$ diacylglyceroldependent protein kinase and the transcription factor Ying Yang 1. Taking into consideration that this transcription factor is as a member of the Polycomb complex and thus, part of repressive and activating chromatin remodeling factors, it might direct the interaction of DNA methyltransferases or dioxygenases of methylated cytosines to their target sequences. Since glial glutamate transporters promoters are targets of Ying-Yang 1, in this contribution, we explored the role of dynamic DNA methylation in the expression and function of glial glutamate transporters. To this end, we used the well-characterized models of primary cultures of chick cerebellar Bergmann glia cells and a human retina-derived Müller glia cell line. A time and dose-dependent increase in global DNA methylation was found upon glutamate exposure. Under hypomethylation conditions, both glial glutamate transporters expression and function were increased. These results, favor the notion that a dynamic methylation program triggered by glutamate in glia cells modulates one of its major functions: glutamate removal.

\section{Introduction}

Glutamate (Glu) is the major excitatory amino acid in the vertebrate brain. It exerts its actions through its binding to specific membrane receptors expressed in neurons and glia cells. Ligand-gated ion channels as well as G protein coupled receptors (GPCR) are activated by this amino acid. The former are known as ionotropic Glu receptors (GRI) and were first subdivided in N-methyl-D-aspartate receptors (GRIN), aamino-3-hydroxy-5-methyl-4-isoxazole propionic acid receptors (GRIA) and kainate receptors (GRIK). These protein complexes are composed of 4 homo or hetero subunits of the corresponding subtype. The differential molecular composition of these receptors, together with diverse posttranscriptional modifications of their corresponding mRNAs and the diverse subunit assembly at the plasma membrane has been a major obstacle in the development of specific ligands [1]. Metabotropic Glu receptors (GRM) are members of Class $\mathrm{C}$ of $\mathrm{G}$ protein- coupled receptors (GPCR) and have been divided accordingly to their primary structure in Class I, II and III [2]. Overstimulation of synaptic and extra synaptic Glu receptors has been linked to neuronal death, a phenomena known as excitotoxicity [3].

A family of Glu membrane transporters of the solute carrier gene family, known as excitatory amino acid transporters (EAATs) regulates Glu extracellular levels. Thus far, five membrane Glu transporters have been characterized. The Glu/aspartate transporter GLAST and the Glu transporter 1 (Glt-1) are mainly expressed in glia whereas the excitatory amino acid carrier (EAAC1), the excitatory amino acid 
transporters 4 and 5 (EAAT4-5) have been described in neurons. The human Glu transporters have been named EAAT $1-5$. Approximately more than $95 \%$ of the brain Glu uptake activity takes place in glia cells (reviewed in [4] ).

Once Glu is internalized into glial cells it is metabolized via glutamine synthetase (GS) to glutamine (GIn) and released in the vicinity of the presynaptic neuron through the reverse function of type $\mathrm{N}$ of sodiumdependent neutral amino acid transporters (SNAT 3,5). GIn is taken up by the presynaptic neurons by an unidentified GIn transporter and de-aminated back to Glu by Glutaminase and packed into synaptic vesicles through vesicular Glu transporters (VGLUTs) completing the so-called Glu/GIn shuttle, a metabolic cascade critically involved in Glu turnover and neuronal availability [5]. Such a metabolic interplay between neurons and glia requires the coordinated expression of numerous proteins [5]. Focusing only in the glia compartment, an activity-dependent change in its protein repertoire is expected from the reported transcriptional and translational control of gene expression upon Glu exposure (reviewed in[6]). In fact, we and others have reported that stimulation of Glu receptors and transporters regulate at the transcriptional [7-9] and translational [10] the expression of components of the Glu/Gln shuttle, such as GLAST and GS.

Taking into consideration that the Yin-Yang 1 (YY-1) transcription factor is involved in the Glu-dependent GLAST transcriptional control [11, 9]and that YY-1 is a mediator to recruit the Polycomb group of proteins and DNA methyltransferases to participate in gene silencing processes [12], in this contribution we decided to explore the plausible involvement of a dynamic DNA methylation mechanism in the Gludependent transcriptional repression of GLAST.

In this context, using the established models of chick cerebellar cultured Bergmann glia cells (BGC) and the human retina-derived Moonfields Institute of Ophthalmology-Müller 1 cell line (MIO-M1), we present herein evidence for a Glu-dependent dynamic DNA methylation/demethylation transcriptional control of GLAST and Glt-1 expression and activity, supporting the notion of an exquisite biochemical coordination of Glu uptake as the framework of glutamatergic transmission.

\section{Materials And Methods}

\section{Materials}

L-Glutamate, phorbol 12-myristate 12-acetate (TPA), valproic acid (VPA), and dihydrokainic acid (DHK) were all obtained from Tocris Biosciences (Ellisville, IL, USA). 5-Aza-2'-deoxycytidine (A3656), D-Aspartic acid (A8881), Bisindolylmaleimide I (203290) and all other chemicals were purchased from Sigma-Aldrich (St. Louis, MO, USA). Anti-YY1 (c-20) (sc-281), anti-TET1 (4F4) (sc-293186), anti-Laminin a/c (sc20681) were obtained from Santa Cruz Biotech (Santa Cruz, CA, USA), anti-DNMT3b (ab2851) and antiEAAT1/GLAST (ab416) were purchased from Abcam Inc. (Cambridge, UK), anti-TET1 (GTX627420), antiGADPH (GTX239) and anti-Tubulin (GTX114) were purchased from GeneTex (Irvine, CA, USA). The monoclonal anti-actin antibody was a generous gift from Prof. Manuel Hernández (Cinvestav, Mexico City). Horseradish peroxidase-linked secondary antibodies and the enhanced chemiluminescence reagent 
(ECL) as well as tissue culture reagents were obtained from GE Healthcare (Carlsbad, CA, USA) and from Gibco by Life Technologies (Carlsbad, CA, USA).

\section{Cell culture}

Primary cultures of cerebellar BGC were prepared from 14-day- old chick embryos (Avimex, Mexico City, Mexico) as previously described and characterized [13]. Cerebella were dissected, cut into small pieces and incubated for $15 \mathrm{~min}$ at $37^{\circ} \mathrm{C}$ in Puck's medium containing trypsin $(0.25 \mathrm{mg} / \mathrm{mL})$ and DNase $(0.08 \mathrm{mg} / \mathrm{mL})$ to dissociate the tissue. The media was removed and substituted with Opti-MEM containing 2.5\% fetal bovine serum (FBS), $2 \mathrm{mM}$ glutamine, and gentamicin $(50 \mu \mathrm{g} / \mathrm{mL})$ for mechanical dissociation. BGC were then recovered by the repeated removal of dissociated cells and diluted to $1 \times 10^{6}$ cells $/ \mathrm{mL}$ and then were seeded in plastic culture dishes. The cultures were maintained at $37^{\circ} \mathrm{C}$ under standard conditions ( $5 \% \mathrm{CO}_{2}$ and $95 \%$ humidity) and used on the 4 th -7 th day after culture.

The MIO-M1 cell line was grown as previously described [14]. The cells were subcultured by detachment with Trypsin-EDTA 10X (5.0 g/L trypsin, $2.0 \mathrm{~g} / \mathrm{L}$ EDTA and $8.5 \mathrm{~g} / \mathrm{L} \mathrm{NaCl})$. After removal of culture medium, $0.05 \%$ Trypsin-EDTA was added, and the cells were incubated at $37{ }^{\circ} \mathrm{C}$ during $2-3$ min until cells were detached without losing adherent characteristics. The reaction was stopped by addition of $10 \%$ fetal bovine serum (FBS) in DMEM. The cells were detached by pipetting, collected in a $15 \mathrm{~mL}$ conic tube, centrifuged at low speed and the supernatant was discharged, the cell pellet was resuspended in DMEM supplemented with $10 \% \mathrm{FBS}, 100 \mathrm{U} / \mathrm{mL}$ penicillin and $100 \mu \mathrm{g} / \mathrm{mL}$ streptomycin. Trypan-stained and live cells were counted by optical microscopy in a Neubauer chamber and viability was expressed as percentage of live cells with reference to the total number of cells. Cells were then seeded in 6-well plates at a density of $1 \times 10^{5}$ cells/well, p60 plates at $1 \times 10^{9}$ cells/plate or in 24-well plates at 250 000-500 000 cells/well and incubated at $37^{\circ} \mathrm{C}$ until reaching the desire confluence.

\section{SDS-PAGE and Western blots}

Confluent monolayers were harvested with phosphate-buffer saline (PBS) $\left(10 \mathrm{mM} \mathrm{K}{ }_{2} \mathrm{HPO}_{4} / \mathrm{KH}_{2} \mathrm{PO}_{4}, 150\right.$ $\mathrm{mM} \mathrm{NaCl}, \mathrm{pH}$ 7.4) containing phosphatase inhibitors ( $10 \mathrm{mM} \mathrm{NaF}, 1 \mathrm{mM} \mathrm{Na}_{2} \mathrm{MoO}_{4}$ and $1 \mathrm{mM}$ $\mathrm{Na}_{3} \mathrm{VO}_{4}$ ). Total protein extraction was performed with RIPA buffer (50 mM Tris-HCl, $1 \mathrm{mM}$ EDTA, $150 \mathrm{mM}$ $\mathrm{NaCl}, 1 \mathrm{mM}$ phenylmethylsulfonylfluoride, $1 \mathrm{mg} / \mathrm{ml}$ aprotinin, $1 \mathrm{mg} / \mathrm{ml}$ leupeptin, $1 \% \mathrm{NP}-40,0.25 \%$ sodium deoxycholate, $10 \mathrm{mM} \mathrm{NaF}, 1 \mathrm{mM} \mathrm{Na}_{2} \mathrm{MoO}_{4}$ and $1 \mathrm{mM} \mathrm{Na}_{3} \mathrm{VO}_{4}$, $\mathrm{pH}$ 7.4). Cytoplasmic protein extraction was performed with buffer A (10 mM HEPES, pH 7.9, 10 mM KCl, 1 mM EDTA, 1 mM EGTA, 1 mM DTT, 1 $\mathrm{mM}$ PMSF and $50 \mathrm{\mu g} / \mu \mathrm{l}$ protein inhibitors cocktail) followed by nuclear protein extraction using buffer $\mathrm{C}$ (20 mM HEPES, pH 7.9, 0.4 mM NaCl, 1 mM EDTA, 1 mM EGTA, 1 mM DTT, 1 mM PMSF and $40 \mu \mathrm{g} / \mu \mathrm{l}$ protein inhibitors cocktail). Cell lysates were denaturized in Laemmli's sample buffer, and equal amount of proteins (approximately $70 \mu \mathrm{g}$ as determined by the Bradford method) were resolved through $10 \%$ or gradient (6-12\%) SDS-PAGE slab gels and then electroblotted to nitrocellulose membranes. Blots were stained with Ponceau $S$ stain to confirm that protein content was equal in all lanes. Membranes were soaked in PBS to remove the Ponceau S and incubated in TBS containing 5\% dried skimmed milk and 
$0.1 \%$ Tween 20 for $2 \mathrm{~h}$ to block the excess of non-specific protein binding sites. Membranes were then incubated overnight at $4^{\circ} \mathrm{C}$ with primary antibodies as indicated in each figure, followed by the respective secondary antibodies incubation for $2 \mathrm{~h}$ at room temperature. Immuno-reactive polypeptides were detected by chemiluminescence with a MicroChemi (DNR Bio-imaging System) charge-coupled device (CCD) imager (DNR; MahaleHaHamisha, Jerusalem, Israel). Densitometry analyses were performed with Image J64 application (NIH; Bethesda, Maryland, USA) and data analyzed with Prism 5, GraphPad Software (San Diego, CA, USA).

\section{Genomic DNA isolation and DNA Methylation Quantification}

Genomic DNA (gDNA) was extracted using the Wizard Genomic DNA Purification Kit (Promega; Madison, WI, USA) according to the instructions provided by the manufacturer. Quality and concentration of samples was evaluated using an Epoch Spectrophotometer (Bio-Tek, USA), and through its integrity analysis in $1.5 \%$ agarose gels. The DNA Colorimetric Quantification Kit (ab117128) (Abcam, Cambridge, UK) was used to determine global DNA methylation of glial cells according to the manufacturer's instructions. Briefly, binding buffer was added to each well then, a negative control, a positive control, or $100 \mathrm{ng}$ of gDNA per reaction were added. The plate was incubated for $90 \mathrm{~min}$, washed, and incubated with the capture antibody for $60 \mathrm{~min}$. The plate was washed and incubated with the detection antibody after which an enhancer solution was added. Finally, the plate was washed and developing solution was added followed by stop solution. Absorbance was determined at $450 \mathrm{~nm}$. The relative methylation status was calculated according to manufacturer's protocol.

\section{RNA extraction and RT-qPCR assay}

Total RNA was extracted with TRIzol reagent (Invitrogen; Carlsbad, CA, USA) according to the manufacturer's protocol. The RNA concentrations were determined by spectrophotometry with Nano-Drop 2000c spectrophotometer (Thermo Fisher Scientific, Waltham, MA, USA). The mRNA levels were analyzed using the KAPA SYBR FAST One-Step (KapaBiosystem; Boston, MA, USA) according to manufacturer's protocol. The conditions of reverse transcription and amplification were $37^{\circ} \mathrm{C}$ during $30 \mathrm{~s}, 42{ }^{\circ} \mathrm{C}$ during 5 min and $95^{\circ} \mathrm{C}$ during $5 \mathrm{~min}$, followed by 40 cycles of amplification: $5 \mathrm{~s}$ at $95^{\circ} \mathrm{C}, 30 \mathrm{~s}$ at $60{ }^{\circ} \mathrm{C}$ and $30 \mathrm{~s}$ at $72{ }^{\circ} \mathrm{C}$; melt curve: $15 \mathrm{~s}$ at $95^{\circ} \mathrm{C}, 1 \mathrm{~min}$ at $60^{\circ} \mathrm{C}$ and $15 \mathrm{~s}$ at $95^{\circ} \mathrm{C}$. Reactions were performed in StepOnePlus Real-Time PCR System (Applied Biosystems; Foster City, California, USA). Data was normalized with GAPDH as an internal control and the relative expression were calculated using the 2 $(\triangle \triangle \mathrm{Ct})$ method. Primer sequences were: DNMT1 forward GGTTCTTCCTCCTGGAGAATG, DNMT1 reverse GTCTGGGCCACGCCGTACTG; DNMT3A forward GGTGCTGTCTCTCTTTGATG, DNMT3A reverse ATGCTTCTGTGTGACGCTG; DNMT3B forward ACCACCTGCTGAATTACTCACG, DNMT3B reverse GATGGCATCAATCATCACTGG; and GAPDH forward CCGGGAAACTGTGGCGTGATGG, GAPDH reverse AGGTGGAGGAGTGGGTGTCGCTGTT.

\section{$\left[{ }^{3} \mathrm{H}\right]-\mathrm{D}-$ Aspartate Uptake}


D-Aspartate uptake was carried out as previously described [15]. Cultured monolayers in 24-well dishes were treated under different stimulus (indicated in the figures) for the indicated time periods. All the treatments were made in complete medium. Once the incubation periods finished, cultured monolayers were washed twice with pre-warmed uptake buffer (HEPES-buffered solution containing $25 \mathrm{mM}$ HEPES, $130 \mathrm{mM} \mathrm{NaCl}, 5.4 \mathrm{mM} \mathrm{KCl}, 1.8 \mathrm{mM} \mathrm{CaCl}_{2}, 0.8 \mathrm{mM} \mathrm{MgCl}_{2}, 33.3 \mathrm{mM}$ glucose, and $1 \mathrm{mM} \mathrm{NaH}_{2} \mathrm{PO}_{4}, \mathrm{pH} 7.4$ ), and were incubated with fresh pre-warmed uptake buffer containing $0.4 \mu \mathrm{Ci} / \mathrm{mL}\left[{ }^{3} \mathrm{H}\right]-\mathrm{D}$-aspartate $\left(\left[{ }^{3} \mathrm{H}\right]-\mathrm{D}\right.$ Asp) (specific activity: $16.5 \mathrm{Ci} / \mathrm{mmol}$, Perkin Elmer, MA, USA). D-Asp (glutamate analogue) was used as it has the advantage of being non-metabolizable while still is taken up by the same transporters systems as Glu. Uptake was finished after $30 \mathrm{~min}$ of incubation and monolayers were washed with ice-cold uptake buffer; cells were lysed with $0.1 \mathrm{~N} \mathrm{NaOH}$. Protein concentration in the lysates was determined with Bradford protein assay (Bio-Rad, CA, USA) and then were transferred to scintillation vials. Radioactivity was measured in a PerkinElmer Tri-Carb 2810TR liquid scintillation counter (PerkinElmer, MA, USA). Experiments were performed in quadruplicates in three-four independent cultures.

\section{Statistical analysis}

All data was first evaluated by the Shapiro-Wilk test to determine normal distribution. If the data was normally distributed a one-way ANOVA test vas used for statistical analysis. If the data were not normally distributed, the non-parametric Kruskal-Wallis test was performed. When these analyses indicated significance a Dunnett's, Bonferroni's or Dunn's post hoc test was used. The Prism 5 software (GraphPad Software, La Jolla, California, USA) was used for all the statistics, all the results are presented as mean \pm standard deviation (SD). In all cases, a $p$-value less than 0.05 was considered statistically significant.

\section{Results}

\section{Glu-dependent DNA methylation in cultured BGC}

In order to gain insight into a plausible effect of Glu exposure in BGC methylome, we exposed BG confluent monolayers to a $1 \mathrm{mM}$ Glu concentration during $24 \mathrm{~h}$. As depicted in Figure 1, a significant increase in the 5-methyl cytosine $(5-\mathrm{mC})$ content was present. The fact that the treatment with two D-Asp concentrations ( $100 \mathrm{mM}$ and $1 \mathrm{mM})$ did not result in a modification of the $\%$ of $5-\mathrm{mC}$ as compared to control cells suggest that the Glu effect is a receptor-mediated response. The exposure to a $4 \mathrm{mM}$ concentration of valproate (an histone deacetylase inhibitor) resulted in an increase in the percentage of 5-mC.

\section{$\left[{ }^{3} \mathrm{H}\right] \mathrm{D}$-Asp uptake under hypomethylating conditions in cultured radial glia}

Taking into consideration the prominent role of YY-1 in the transcriptional regulation of the chglast gene [9] and the reported association of this transcription factor with DNMT3 [12,16], together with the results shown in Figure 1, we decided to explore the effect of the treatment with an hypomethylating agent, 5-Aza-deoxycytidine (5-Aza) in the [ $\left.{ }^{3} \mathrm{H}\right] \mathrm{D}$-Asp uptake activity, that in BGC is carried out exclusively by GLAST/EAAT1 [15]. As clearly shown in panel A of Figure 2, a $24 \mathrm{~h}$ exposure to $10 \mathrm{mM}$ 5-Aza 
concentration results in an augmentation of $\left[{ }^{3} \mathrm{H}\right] \mathrm{D}$-Asp uptake. Interestingly, this increase in the uptake is sensitive to a $30 \mathrm{~min}$ exposure to $1 \mathrm{mM}$ Glu. Previous studies of our group have demonstrated that a short-term Glu exposure (30 min), down regulates GLAST activity in a transporter-dependent manner via a decrease in $\mathrm{V}_{\text {Max }}$ linked to a reduction in plasma membrane transporters $[17,18]$. Therefore, the 5-Aza effect is most likely the result of an increase in GLAST levels at the plasma membrane that a 30 min exposure to Glu is capable to overcome. The HDAC inhibitor VPA augments the uptake activity [7] and this effect is enhanced by 5-Aza, pointing out an increase in chglast transcription under hypomethylating conditions (Figure 2, panel A). A very similar response was obtained when the preincubation period with 5-Aza was extended to $48 \mathrm{~h}$ (Figure 2, panel B). Furthermore, a $72 \mathrm{~h}$ 5-Aza pretreatment still showed a pronounced increase in $\left[{ }^{3} \mathrm{H}\right] \mathrm{D}$-Asp uptake (Figure 2, panel $\mathrm{C}$ ).

With the idea to support our hypothesis that chglast transcription was indeed promoted under hypomethylating conditions, we decided to perform the $\left[{ }^{3} \mathrm{H}\right] \mathrm{D}$-Asp uptake assays in the presence of the Glt-1 blocker dihydrokainate (DHK). The results are shown in panel D of Figure 2, as already reported in BGC, no reduction of [ $\left.{ }^{3} \mathrm{H}\right] \mathrm{D}$-Asp uptake is detected in cells preincubated with DHK [15]. To our surprise in the cells exposed for $24 \mathrm{~h}$ to 5 -Aza, a reduction of the enhanced uptake is present under DHK, suggesting that both transporters GLAST and Glt-1 are upregulated when the activity of DNMT3 is sequestered by 5Aza (Figure 2, panel D).

\section{GLAST expression is down regulated by Glu through a DNA methylation event}

The described results prompted us to evaluate GLAST protein levels under 5-Aza. As expected from the uptake experiments described in Figure 2, an increase in GLAST levels is present after a $48 \mathrm{~h}$ 5-Aza treatment, as already documented, the exposure to $1 \mathrm{mM}$ Glu reduces GLAST protein levels (Figure 3, panel A) [17,9]. Interestingly, exposure to D-Asp (100 mM, $1 \mathrm{mM})$ also reduces GLAST protein levels. Taking into consideration that $Y Y-1$ is involved in s/c1A3 (glast) and slc1A2(g/t-1) transcriptional regulation $[19,20,9]$ we explored the effect of a $1 \mathrm{mM}$ Glu exposure for 12, 24 and $48 \mathrm{~h}$ in $\mathrm{YY}-1$ nuclear levels. A clear increase in nuclear YY-1 is present after a $24 \mathrm{~h}$ Glu treatment and it is maintained up to 48 $\mathrm{h}$ in good correlation the 5-Aza augmentation on GLAST and the $\left[{ }^{3} \mathrm{H}\right] \mathrm{D}$-Asp uptake activity (Figure 3 , panel B). In fact, 5-Aza exposure also augments nuclear YY-1 content after $24 \mathrm{~h}$ (Figure 3, panel C). These results opened the possibility that Glu treatment would increase DNMT3 protein levels and indeed this is the case (Figure 4, panel A) and particularly DNMT3B (Figure 4, panel B), suggesting that the reported YY-1 mediated Glu-dependent chglast transcriptional repression is in fact, mediated through a dynamic promoter methylation. In line with this interpretation is the fact that Glu exposure does not change the levels of the ten eleven translocator 1 (TET-1), while, as expected, 5-Aza does (Figure 4, panel C).

\section{Glu-dependent increase in DNA methylation in MIO-M1 cells}

In order to explore the possibility that the described results would be relevant for other species besides Gallus gallus, we decided to explore the percentage of 5-mc after Glu, Asp and phorbol dibutyrate (TPA) 
treatments in the human derived retina Müller cells, Mio-M1 cells. Taking into consideration that these cells are radial glia cells just as BGC and that we and others have found the Glu triggers the similar signaling pathways in both cultures (reviewed in [6]), it was not surprising that we could detect a significant increase in the percentage 5-mC content in Müller cells exposed for $24 \mathrm{~h}$ to $1 \mathrm{mM}$ Glu (Figure $5)$.

\section{YY-1 is involved in GLAST down regulation in MIO-M1 cells}

In line with the results described above, Glu down regulates GLAST protein levels in a in the human retina Müller cells. Interestingly, the exposure to 500 nM TPA, used here as a PKC activator also decreases GLAST protein after a $24 \mathrm{~h}$ exposure (Figure 6, panel A). YY-1 is increased in the nuclear fraction of cells exposed for $24 \mathrm{~h}$ (panel B) to Glu. Of relevance is to mention that this nuclear YY-1 nuclear accumulation is sensitive to the PKC blocker, bisindolylmaleimide I (Bis). Whether the Glu effect is transporter or receptor-mediated, it is not clear from these results since we could detect a significant reduction in GLAST protein levels upon a $100 \mathrm{mM}$ D-Asp treatment, nevertheless, no clear YY-1 nuclear translocation was found. Other experiments, clearly beyond the scope of this communication, are needed to fully characterize GLAST down regulation in retina radial glia cells.

Since MGC express both GLAST and Glt-1, we decided to explore Glt-1 expression after 5-Aza treatment. Hypomethylating conditions increase Glt-1 protein levels, supporting the notion that in radial glia cells, Glu transporters are dynamically modulated through methylation/demethylation processes (panel C, Figure 6).

\section{$\left[{ }^{3} \mathrm{H}\right]-\mathrm{D}$ Asp transport regulation in Mio-M1 cells}

In order to gain insight into the functional effect of the regulation of the glial Glu transporters GLAST and Glt-1 protein levels in Müller cells, we explored the $\left[{ }^{3} \mathrm{H}\right] \mathrm{D}$-Asp uptake activity. As shown in panel A of Figure 7, more the $80 \%$ of the Asp uptake activity is mediated by GLAST, since a $100 \mathrm{mM}$ DHK concentration reduces approximately $20 \%$ of the uptake activity. A 30 min exposure to either Glu or Asp, reduces the ${ }^{[} \mathrm{H}$ ] D-Asp activity as in BGC. Hypomethylation conditions increases the uptake after 24 and $48 \mathrm{~h}$ of 5-Aza exposure, and this augmentation is prevented by a $30 \mathrm{~min}$ treatment with Glu. The fact that the VPA and 5-Aza effects are additive, strongly suggest that the increased activity is the result of a demethylation phenomenon. Finally, in Müller cells, the increase in Glu transporter function is almost entirely the result of an increase in Glt-1 functional expression (Figure 7, panel D). This result is in sharp contrast to BGC, in which the augmentation in the uptake is mostly the result of a GLAST up regulation (Figure 2, panel D).

\section{Discussion}

Once regarded as an almost permanent form of transcriptional repression, DNA methylation has emerged as a dynamic process in the central nervous system development that is also critically involved in brain insults. Broad-based transcriptional suppression has been linked to brain insults like ischemic tolerance 
due to the regulation of gene silencing proteins of the Polycomb family [21]. Polycomb proteins are epigenetic regulators that maintain the transcriptional repression of their target genes [22]. These genes are repressed under certain circumstances, but become active in response to cell signaling mechanisms associated to higher brain functions such as learning and memory [23].

Methylation of cytosine nucleotides has been considered a strong and practically a rarely modified epigenetic mark. Nevertheless, a rapid and dynamic methylation of specific genes is critically involved in behavioral plasticity $[24,25]$. In vertebrates, methylation at symmetric $\mathrm{CpG}$ dinucleotides is a primary epigenetic mechanism for gene transcriptional regulation, along with histone modifications such as methylation, acetylation, SUMOylation, ubiquitination and phosphorylation [26]. The addition of a methyl group to cytosine is catalyzed by three DNA methyltransferases: DNMT1, DNMT3a and DNMT3b. DNMT1 is the maintenance DNA methyltransferase while the other two are regarded as de novo DNA methyltransferases. Since this enzymatic activity preserves the initial repression process mediated by transcription factors and are recruited through the Polycomb proteins of which YY- 1 is a member, we explored here the plausible involvement of this epigenetic mechanism in the gene expression regulation of the major Glu transporter present in radial glia cells: GLAST [3].

Glutamatergic transmission is the most abundant excitatory system in the vertebrate brain and is a good example of the involvement of glia cells in synaptic transactions. This interpretation relays in the fact that the bulk of Glu uptake activity resides in the glial compartment driven by the glial enriched transporters namely EAAT1/GLAST and EAAT2/Glt-1 [20]. Although the functionality and existence of the Glu/GIn shuttle has been debated over the years (see for example, [21]), the efficient coupling of Glu uptake, GS activity and GIn release in radial glia that wraps glutamatergic synapses in the cerebellum, retina, auditory brainstem, and the calyx of the Held synapse, is evident [5, 7, 23-25]. It has been using appropriate systems, like cultured BGC and Müller glia cell lines that we and others have demonstrated a coupling between EAAT activity and GIn release, fundamental for Glu turnover and in fact, for glutamatergic transmission [27]. In this scenario, a tight regulation of glial Glu transporters gene expression and localization in specific plasma membrane locations is expected (reviewed in [4]).

Taking into consideration the prominent role of YY-1 in the transcriptional regulation of glial Glu transporters $[19,9]$ we decided to explore the involvement of a dynamic DNA methylation process, triggered by Glu, in the expression and function of GLAST, the prominent transporter in radial glia cells. To this end, we first sought to explore the global DNA methylation pattern in response to the exposure to Glu. A significant increase in the percentage of $5-\mathrm{mC}$ content was found. If this differential DNA methylation pattern would have an impact into the most important glia cell function, then, the $\left[{ }^{3} \mathrm{H}\right] \mathrm{D}$-Asp uptake activity would have to be affected by an hypomethylating environment. Through the use of 5-Aza, we "sequestered" the DNMT3B activity, and under those circumstances, GLAST protein levels and activity were upregulated.

In an effort to support the idea of a dynamic methylation process as a regulator of GLAST expression and consequently of its function, we used an specific Glt-1 blocker to demonstrate that in radial glia cells, 
hypomethylating conditions would enhance GLAST function. To our surprise, DHK reduced by $16 \%$ the recorded increase in $\left[{ }^{3} \mathrm{H}\right]$ D-Asp uptake activity in BGC cultures (Fig. 2). This effect is more pronounced in MIO-M1 cells in which apparently, hypomethylating conditions augments Glu uptake through an upregulation of Glt-1 (Fig. 7). These differential results might represent the functional diversity between the cerebellum and retina.

At this stage, it is tempting to speculate that under control conditions, Glt-1 expression is repressed in radial glia cells in a Glu-dependent manner, in support of this interpretation is the fact that Glu treatment augments DNMT3B expression (Fig. 4).

The methylation sites in the s/c1A3 (glast) and slc1A2(g/t-1) promoters is not known at this moment, but this would certainly be addressed in future investigations in our lab. Targeted demethylation of these promoters might prove to be a novel therapeutic tool to increase Glu uptake in brain insults such as stroke.

In summary, we present here biochemical evidence of the involvement of a dynamic DNA methylation/demethylation process in the gene expression regulation of glial Glu transporters. Work currently in progress in our lab is aimed at the characterization of the signaling cascades involved in Gludependent DNMT3 upregulation as well as in the characterization of its functional consequences in terms of radial glia physiology,

\section{Declarations}

Acknowledgments. The authors acknowledge the technical assistance provided by Luis Cid. AG. Rodriguez-Campuzano is supported by a Conacyt-Mexico PhD scholarship.

Author's contributions. AG. Rodríguez-Campuzano and A. Ortega designed experiments, analyzed data, prepared the figures and wrote the manuscript. LC. Hernández-Kelly and A. Ortega supplied reagents and together with A. Rodríguez-Campuzano discussed had a key role in the data discussion and the manuscript revision. All authors have approved the final manuscript.

Funding. This work was supported by grant 255087 from Consejo Nacional de Ciencia y Tecnología (Conacyt) to A. Ortega.

Data availability. The datasets used and analyzed in this study are available from the corresponding author on reasonable request.

\section{Compliance with Ethical Standards}

Conflict of interest. The authors declare that they do not have conflicts of interest.

Ethics Approval and Consent to Participate. All procedures related to animal use were approved by the Ethics Committee for Animal Experimentation of Cinvestav. 
Consent for Publication. All authors consent to the publication of the current data.

Code Availability. Not applicable.

\section{References}

1. Mayer ML (2011) Emerging models of glutamate receptor ion channel structure and function. Structure (London, England: 1993) 19 (10):1370-1380. doi:https://doi.org/10.1016/j.str.2011.08.009

2. Sengmany K, Gregory KJ (2016) Metabotropic glutamate receptor subtype 5: molecular pharmacology, allosteric modulation and stimulus bias. Br J Pharmacol 173(20):3001-3017. doi:https://doi.org/10.1111/bph.13281

3. Zhou Y, Danbolt NC (2014) Glutamate as a neurotransmitter in the healthy brain. Journal of neural transmission (Vienna, Austria: 1996) 121 (8):799-817. doi:https://doi.org/10.1007/s00702-014$1180-8$

4. Rodríguez-Campuzano AG, Ortega A (2021) Glutamate transporters: Critical components of glutamatergic transmission. Neuropharmacology 192:108602.

doi:https://doi.org/10.1016/j.neuropharm.2021.108602

5. Martínez-Lozada Z, Guillem AM, Flores-Méndez M, Hernández-Kelly LC, Vela C, Meza E, Zepeda RC, Caba M, Rodríguez A, Ortega A (2013) GLAST/EAAT1-induced glutamine release via SNAT3 in Bergmann glial cells: evidence of a functional and physical coupling. Journal of neurochemistry 125(4):545-554. doi:https://doi.org/10.1111/jnc.12211

6. Martínez-Lozada Z, Ortega A (2015) Glutamatergic Transmission: A Matter of Three. Neural plasticity 2015:787396. doi:https://doi.org/10.1155/2015/787396

7. Aguirre A, López T, López-Bayghen E, Ortega A (2000) Glutamate regulates kainate-binding protein expression in cultured chick Bergmann glia through an activator protein-1 binding site. J Biol Chem 275(50):39246-39253. doi:https://doi.org/10.1074/jbc.M002847200

8. Gegelashvili G, Schousboe A (1997) High affinity glutamate transporters: regulation of expression and activity. Mol Pharmacol 52(1):6-15. doi:https://doi.org/10.1124/mol.52.1.6

9. Rosas S, Vargas MA, López-Bayghen E, Ortega A (2007) Glutamate-dependent transcriptional regulation of GLAST/EAAT1: a role for YY1. Journal of neurochemistry 101(4):1134-1144. doi:https://doi.org/10.1111/j.1471-4159.2007.04517.x

10. Tiburcio-Félix R, Escalante-López M, López-Bayghen B, Martínez D, Hernández-Kelly LC, Zinker S, Hernández-Melchor D, López-Bayghen E, Olivares-Bañuelos TN, Ortega A (2018) GlutamateDependent Translational Control of Glutamine Synthetase in Bergmann Glia Cells. Mol Neurobiol 55(6):5202-5209. doi:https://doi.org/10.1007/s12035-017-0756-3

11. Pajarillo E, Johnson J Jr, Rizor A, Nyarko-Danquah I, Adinew G, Bornhorst J, Stiboller M, Schwerdtle T, Son DS, Aschner M, Lee E (2020) Astrocyte-specific deletion of the transcription factor Yin Yang 1 in murine substantia nigra mitigates manganese-induced dopaminergic neurotoxicity. J Biol Chem 295(46):15662-15676. doi:https://doi.org/10.1074/jbc.RA120.015552 
12. Ko CY, Hsu HC, Shen MR, Chang WC, Wang JM (2008) Epigenetic silencing of CCAAT/enhancerbinding protein delta activity by $Y Y 1 /$ polycomb group/DNA methyltransferase complex. J Biol Chem 283(45):30919-30932. doi:https://doi.org/10.1074/jbc.M804029200

13. Ortega A, Eshhar N, Teichberg VI (1991) Properties of kainate receptor/channels on cultured Bergmann glia. Neuroscience 41(2-3):335-349. doi:10.1016/0306-4522(91)90331-h

14. Limb GA, Salt TE, Munro PM, Moss SE, Khaw PT (2002) In vitro characterization of a spontaneously immortalized human Müller cell line (MIO-M1). Investig Ophthalmol Vis Sci 43(3):864-869

15. Ruiz M, Ortega A (1995) Characterization of an $\mathrm{Na}(+)$-dependent glutamate/aspartate transporter from cultured Bergmann glia. Neuroreport 6(15):2041-2044. doi:10.1097/00001756-19951001000021

16. Hervouet E, Vallette FM, Cartron PF (2009) Dnmt3/transcription factor interactions as crucial players in targeted DNA methylation. Epigenetics 4(7):487-499. doi:10.4161/epi.4.7.9883

17. González-Mejia ME, Morales M, Hernández-Kelly LC, Zepeda RC, Bernabé A, Ortega A (2006) Glutamate-dependent translational regulation in cultured Bergmann glia cells: involvement of p70S6K. Neuroscience 141(3):1389-1398. doi:10.1016/j.neuroscience.2006.04.076

18. Martínez D, García L, Aguilera J, Ortega A (2014) An acute glutamate exposure induces long-term down regulation of GLAST/EAAT1 uptake activity in cultured Bergmann glia cells. Neurochem Res 39(1):142-149. doi:10.1007/s11064-013-1198-6

19. Karki P, Kim C, Smith K, Son DS, Aschner M, Lee E (2015) Transcriptional Regulation of the Astrocytic Excitatory Amino Acid Transporter 1 (EAAT1) via NF-KB and Yin Yang 1 (YY1). J Biol Chem 290(39):23725-23737. doi:10.1074/jbc.M115.649327

20. Karki P, Webb A, Smith K, Johnson J Jr, Lee K, Son DS, Aschner M, Lee E (2014) Yin Yang 1 is a repressor of glutamate transporter EAAT2, and it mediates manganese-induced decrease of EAAT2 expression in astrocytes. Molecular cellular biology 34(7):1280-1289. doi:10.1128/mcb.01176-13

21. Stapels M, Piper C, Yang T, Li M, Stowell C, Xiong Z-g, Saugstad J, Simon RP, Geromanos S, Langridge J, Lan J-q, Zhou A (2010) Polycomb Group Proteins as Epigenetic Mediators of Neuroprotection in Ischemic Tolerance. 3 (111):ra15-ra15. doi:10.1126/scisignal.2000502 \%J Science Signaling

22. Ghotbi E, Ye P, Ervin T, Kum A, Benes J, Jones RS (2021) Polycomb-group recruitment to a Drosophila target gene is the default state that is inhibited by a transcriptional activator. Sci Adv 7 (29). doi:10.1126/sciadv.abg1556

23. Morris MJ, Monteggia LM (2014) Role of DNA methylation and the DNA methyltransferases in learning and memory. Dialog Clin Neurosci 16(3):359-371. doi:10.31887/DCNS.2014.16.3/mmorris

24. Halder R, Hennion M, Vidal RO, Shomroni O, Rahman R-U, Rajput A, Centeno TP, van Bebber F, Capece V, Vizcaino JCG, Schuetz A-L, Burkhardt S, Benito E, Sala MN, Javan SB, Haass C, Schmid B, Fischer A, Bonn S (2016) DNA methylation changes in plasticity genes accompany the formation and maintenance of memory. Nat Neurosci 19(1):102-110. doi:10.1038/nn.4194 
25. Tognini P, Napoli D, Tola J, Silingardi D, Della Ragione F, D'Esposito M, Pizzorusso T (2015) Experience-dependent DNA methylation regulates plasticity in the developing visual cortex. Nat Neurosci 18(7):956-958. doi:10.1038/nn.4026

26. Jin B, Li Y, Robertson KD (2011) DNA methylation: superior or subordinate in the epigenetic hierarchy? Genes cancer 2(6):607-617. doi:10.1177/1947601910393957

27. Tani H, Dulla CG, Farzampour Z, Taylor-Weiner A, Huguenard JR, Reimer RJ (2014) A local glutamateglutamine cycle sustains synaptic excitatory transmitter release. Neuron 81(4):888-900. doi:10.1016/j.neuron.2013.12.026

\section{Figures}




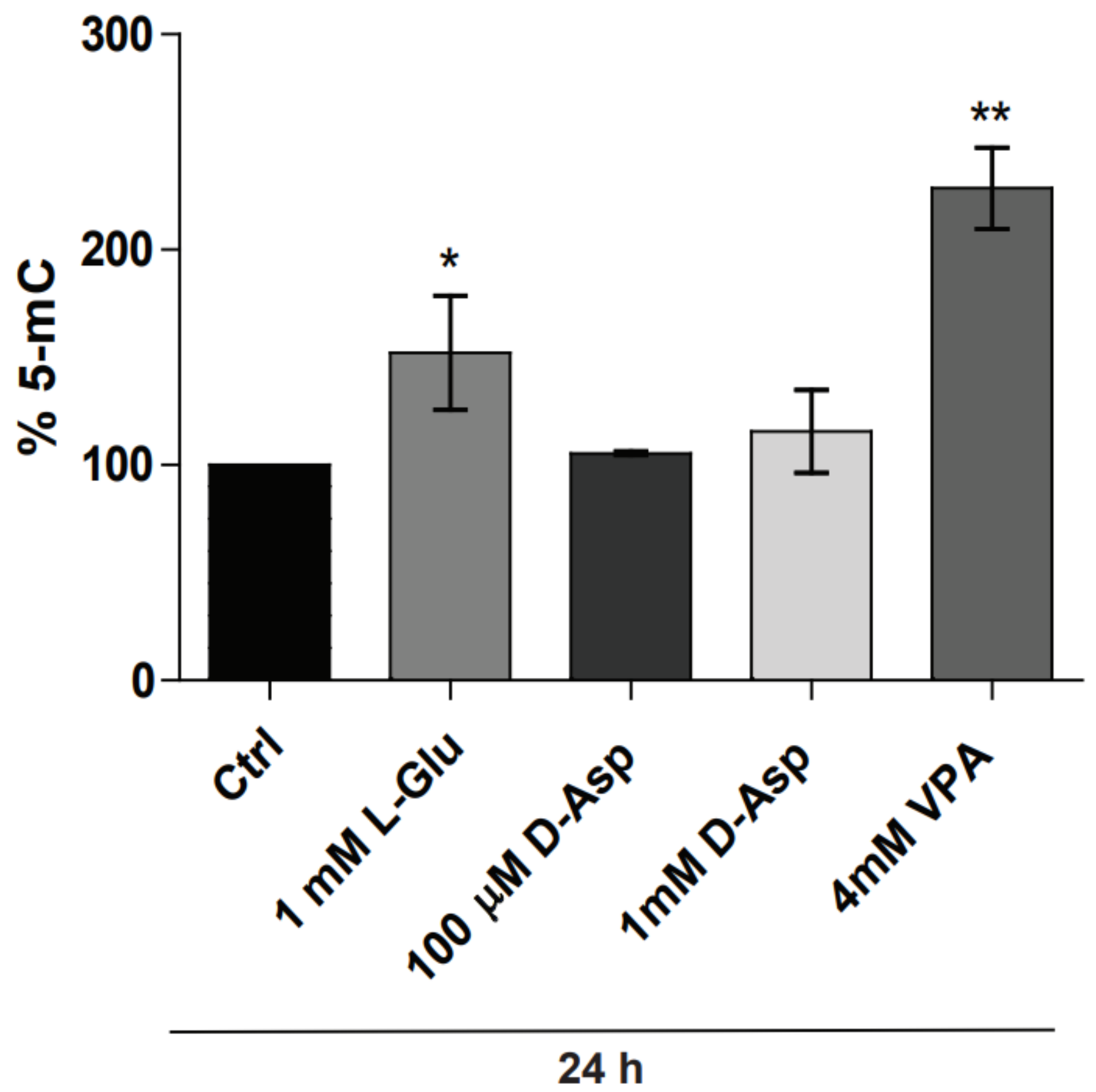

Figure 1

L-Glutamate increases global DNA methylation in glial cells. Global DNA methylation as measured by the production of 5-methylcytosine (5-mC) under different stimuli during 24h in BGC. Graph present changes in the percentage of methylated cytosine. Values are means \pm standard deviation (SD), from at least three independent experiments, analyzed by one-way anova and Dunnett's multiple comparison, where * $\mathrm{p}<$ 0.05 and ${ }^{*} \mathrm{p}<0.001$. 
A)
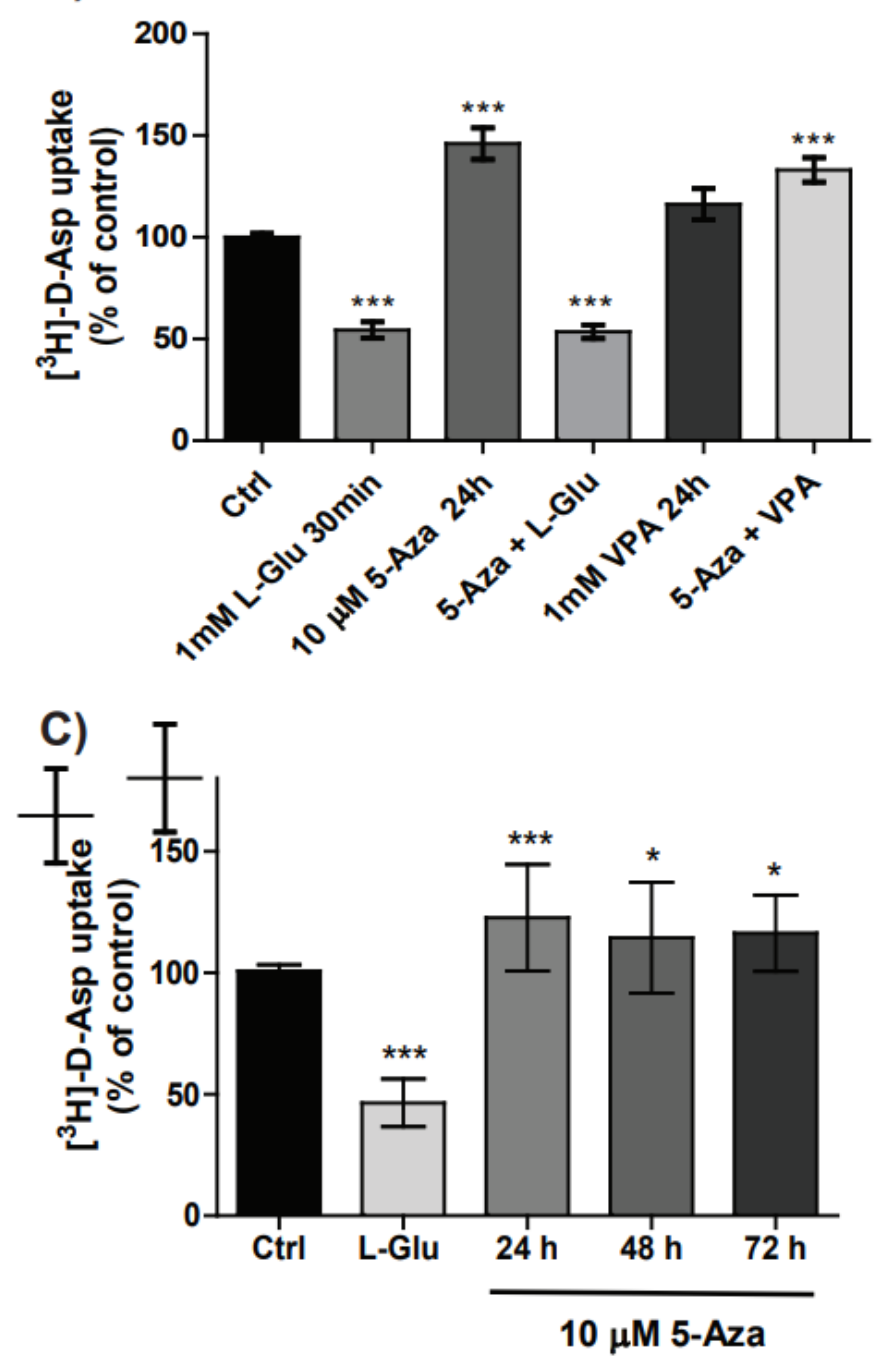

B)

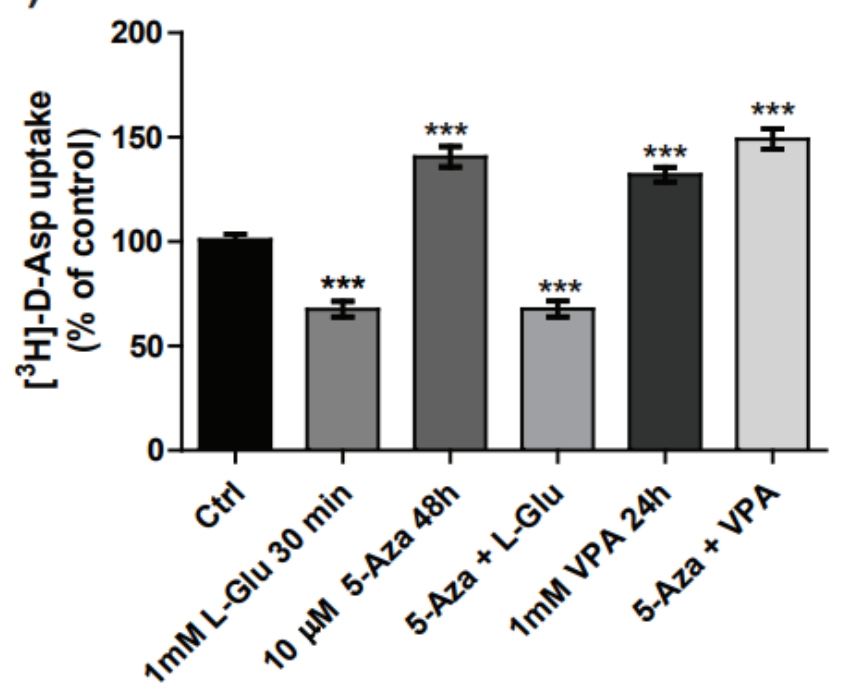

D)

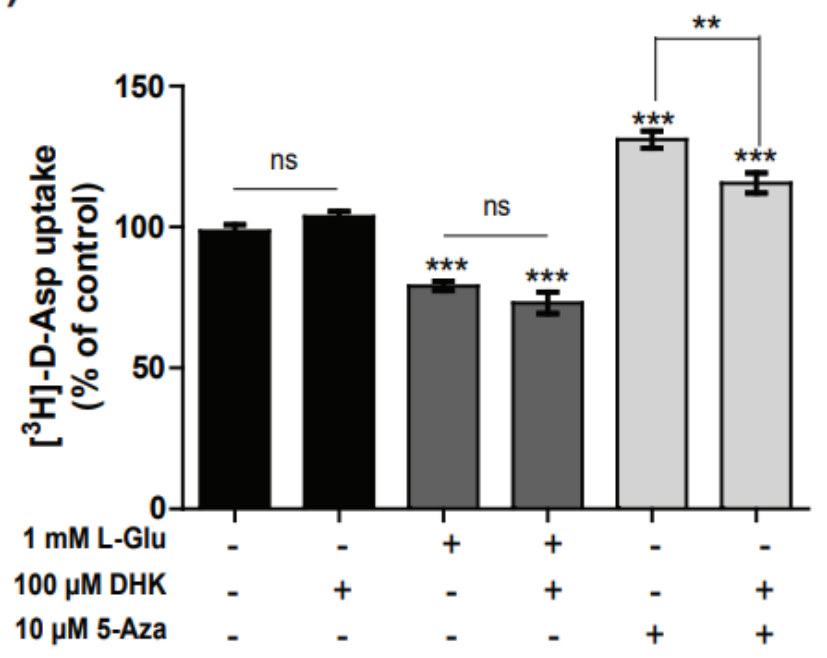

Figure 2

GLAST activity increases under a hypomethylating condition in BGC. Using a pharmacologic approach, we evaluated the activity of the expected glutamate transporter in BGC, GLAST by [H3]-D-Aspartate uptake assay. We treated cells with 5-Aza-2'-deoxycytidine (5-Aza) a nucleoside inhibitor that following its incorporation into DNA traps DNMTs by covalent binding of the enzyme to the DNA and thereby blocking DNMTs function irreversibly at other sites. A) and B) are the same treatment conditions differing in 5-Aza temporality treatment ( $24 \mathrm{~h}$ and $48 \mathrm{~h}$, respectively): Ctrl, $1 \mathrm{mM} \mathrm{L-Glu} 30 \mathrm{~min}, 10 \mu \mathrm{M}$ 5-Aza, $1 \mathrm{mM}$ VPA, plus the combined effect of 5 -Aza $24 \mathrm{~h}$ or $48 \mathrm{~h}$ pre-treatment followed by $1 \mathrm{mM}$ L-Glu 30 min or $1 \mathrm{mM}$ VPA $24 \mathrm{~h}$. C) Treatments with $10 \mu \mathrm{M}$ 5-Aza for different time periods, having $1 \mathrm{mM}$ L-Glu and $1 \mathrm{mM}$ D-Asp as well characterized negative controls of [H3]-D-Asp uptake in BGC. D) Given the increased uptake values after $10 \mu \mathrm{M}$ 5-Aza treatments, we decided to evaluate the effect of a EAAT2 (GLT-1)-selective non-transportable inhibitor, dihydrokainic acid (DHK, $100 \mu \mathrm{M})$, and surprisingly we had a slightly, but significant uptake decrease $(\approx 16 \%)$ after DHK treatment in 5-Aza pre-treated cells. Results of three independent experiments in quadruplicate. Bars represent means \pm SD analyzed by one-way ANOVA with Dunnett's 
multiple comparison, $\star \star \star ~ P \varangle 0.0001$. In (D) we compared all treatments with Bonferroni's multiple comparison where *** $\mathrm{P} \otimes 0.0001$ and ${ }^{* *} \mathrm{p}<0.007$.
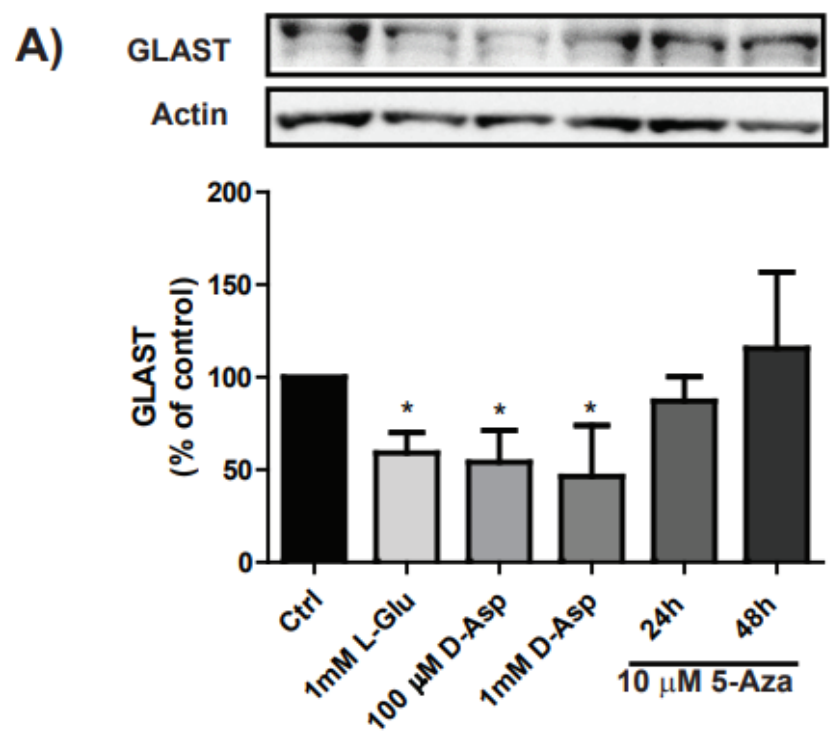

B)
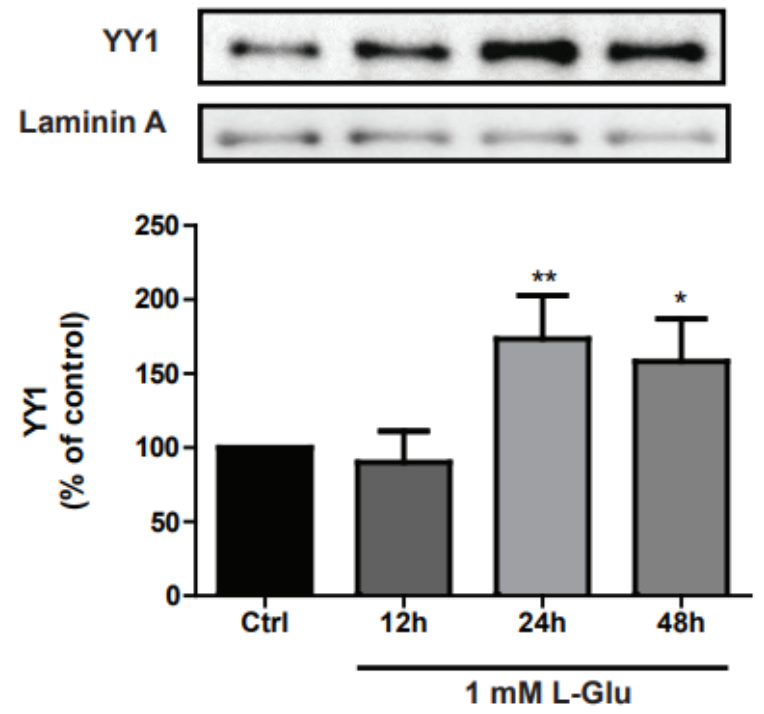

C)
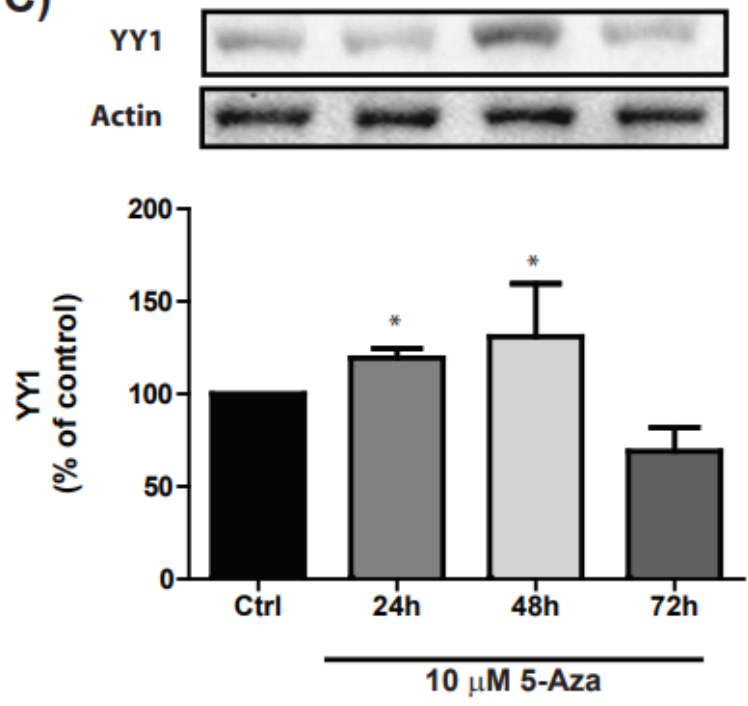

Figure 3

DNA methylation status modifies GLAST, YY1, DNMT3B and TET1 protein levels. A) Evaluation of GLAST protein levels in BGC stimulated with L-Glu and its non-metabolizable analog D-Asp during 24h and 5-Aza during 24 and 48h treatment. B) Nuclear YY1 increased levels during long exposure to L-Glu 1mM. C) Levels of nuclear YY1 on BGC treated with 5-Aza at different time points. D) Increased levels of DNMT3B on L-Glu treatment. E) TET1 levels on L-Glu and 5-Aza treatment during 24h. Laminin A and $\beta$-actin were used as loading controls for nuclear and total protein extracts, respectively. Results of at least three independent experiments, analyzed with Kruskal-Wallis test and a Dunn's multiple comparison where $p$ $\star \star \star<0.0001, p * \star<0.001$. As well as a one-way Anova with a Bonferroni's multiple comparison. 


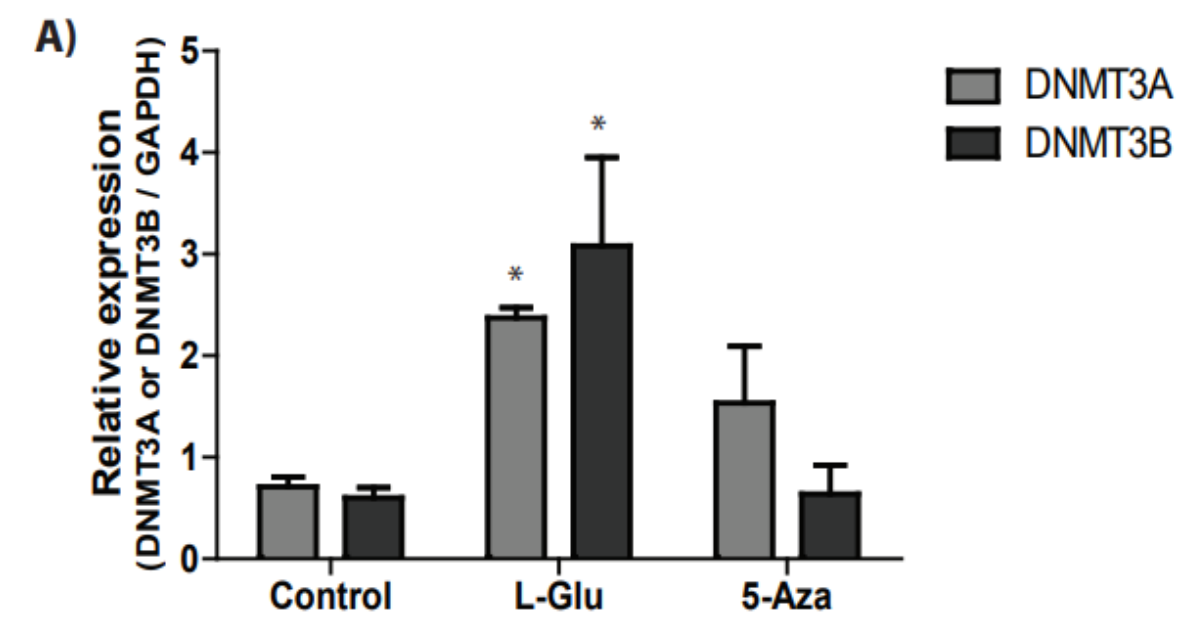

B)
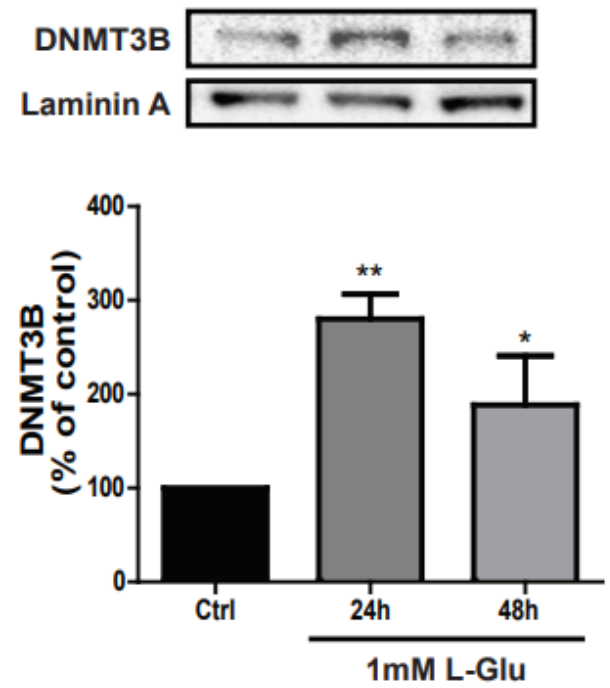

C)
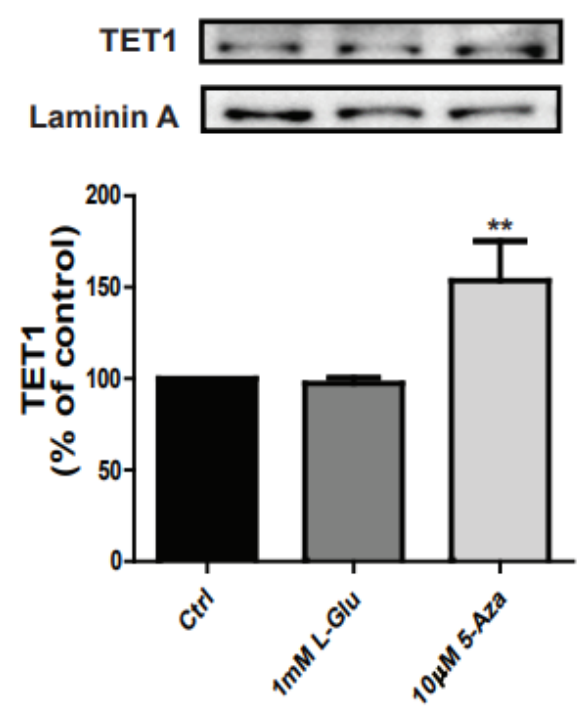

Figure 4

Glutamate modifies de novo DNMTs in Bergmann glia. A) Relative expression of de novo DNMTs after 24 $\mathrm{h}$ treatment with L-Glu $1 \mathrm{mM}$ and 5-Aza $10 \mu \mathrm{M}$, both DNMT3 A and B were increased in L-Glu treated cells, while, in 5-Aza no significant differences were found. (B) since DNMT3B seems to be the most affected enzyme after L-Gu treatment, DNMT3B protein levels were evaluated and as expected this where increased. As a counterpart of the processes of methylation, DNA de-methylation in the CNS underlies in the activity of Ten-eleven translocation enzyme 1 (TET1), after $24 \mathrm{~h}$ treatment with L-Glu no changes were found, while in 5-Aza treated cells, TET1 was increased. The bars represent the mean \pm standard deviation from at least three independent experiments. ${ }^{*} \mathrm{p} \otimes 0.05$. 


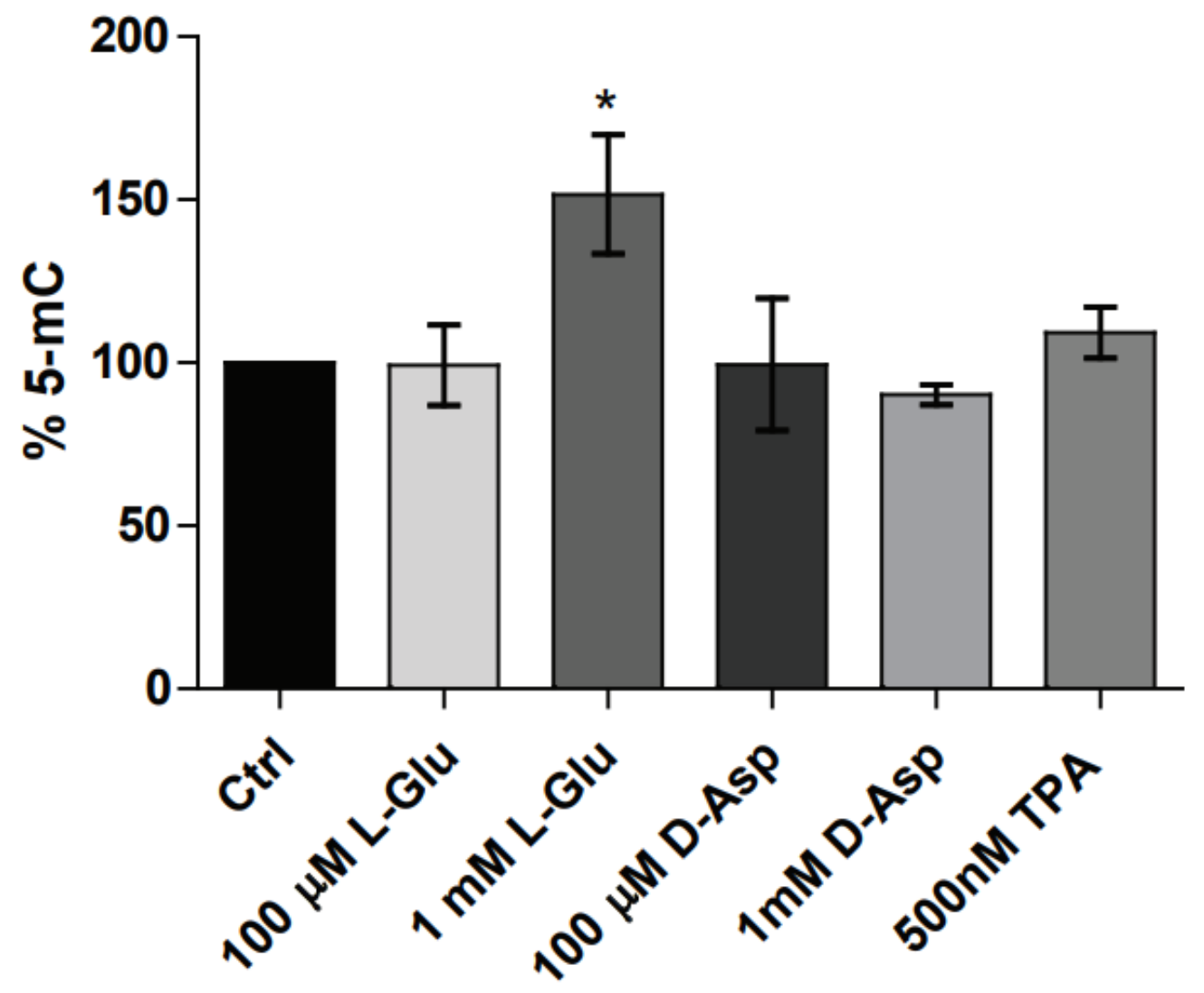

Figure 5

Global DNA methylation levels in MIO-M1 cells. Global DNA methylation as measured by the production of 5-methylcytosine (5-mC) under different stimuli during 24h in MIO-M1 cells. Two concentrations of LGlu and D-Asp were evaluated, where only L-Glu $1 \mathrm{mM}$ had an increased in the $\% 5 \mathrm{mC}$. TPA $500 \mathrm{nM}$ was used as a control of PKC activation since the expression regulation of GLAST in these cells is not well characterized. Graph present changes in the percentage of methylated cytosine. Values are means \pm standard deviation (SD), from at least three independent experiments, analyzed by one-way Anova and Dunnett's multiple comparison, where ${ }^{*} p<0.05$ and ${ }^{* *} p<0.001$. 
A)
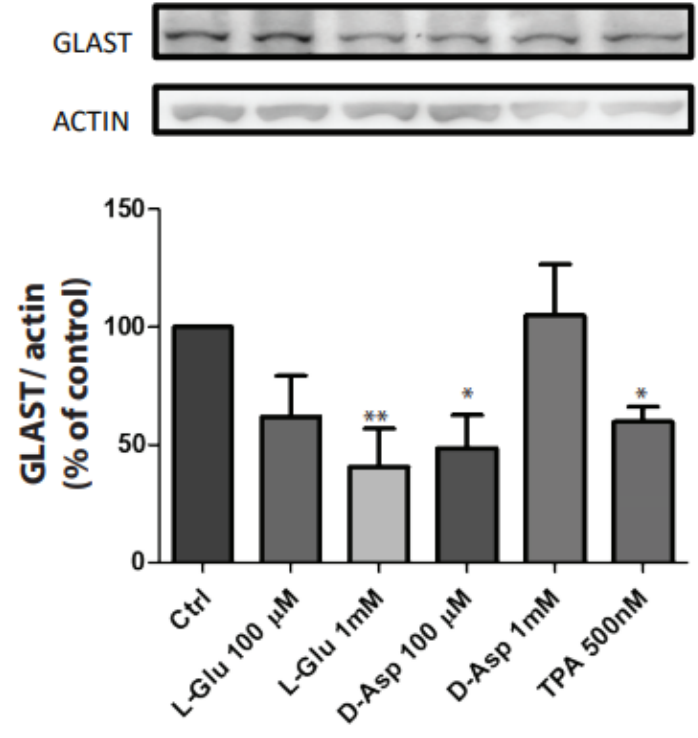

B)

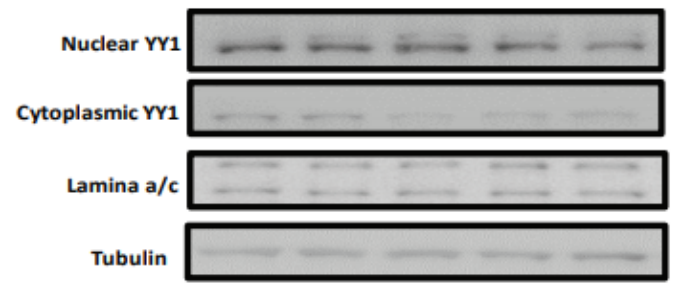

C)

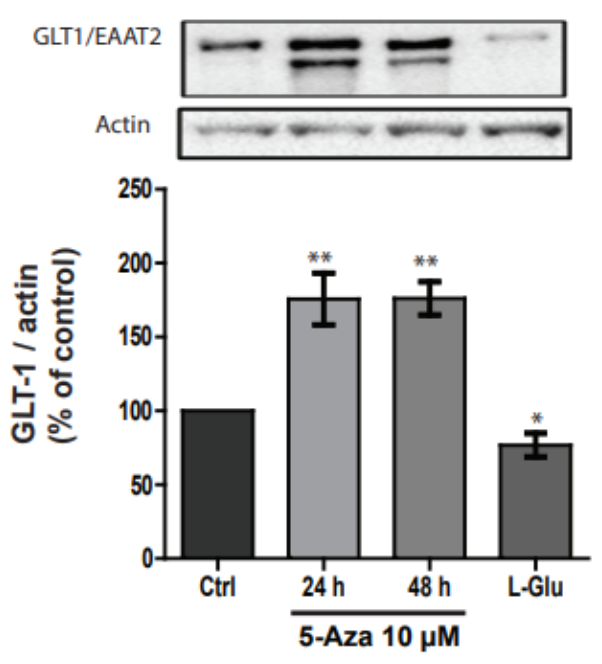

Figure 6

YY1 is implicated in GLAST expression under glutamatergic stimulation in MIO-M1 cells. Glast decrease in L-Glu and D-Asp treated cells during $24 \mathrm{~h}$ demonstrates the same expression behavior as in BGC (A), as nuclear YY1 levels increase under the same conditions (B) and under different L-Glu concentrations treatments (C), during 24h. However, these cells express some levels of GLT1 under normal and glutamatergic conditions (D), adding a level of complexity in understanding glutamate transporters in these cells. Results of at least three independent experiments, analyzed with Kruskal-Wallis test and a Dunnett's multiple comparison where $p * * *<0.0001, p^{* *}<0.001$ and $* P<0.05$. 
A)

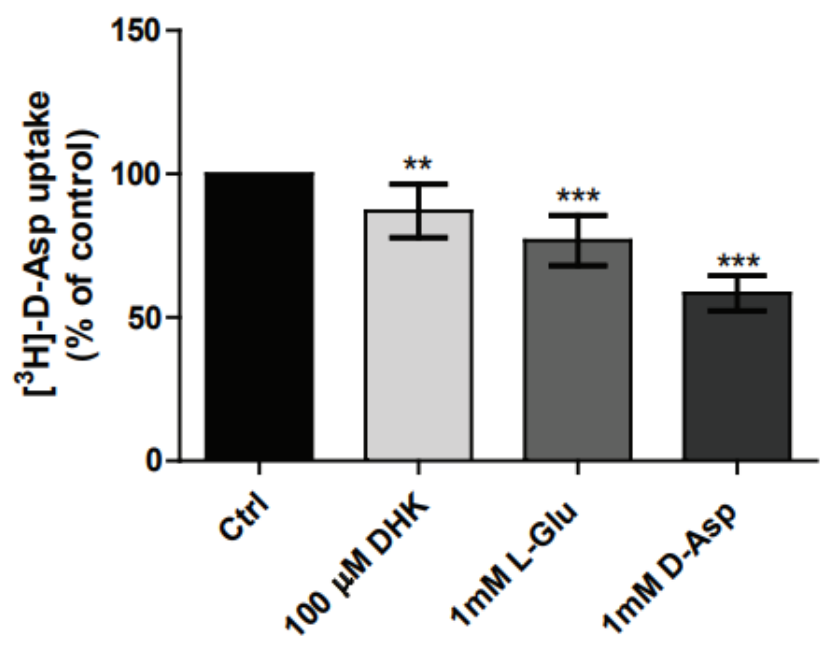

C)

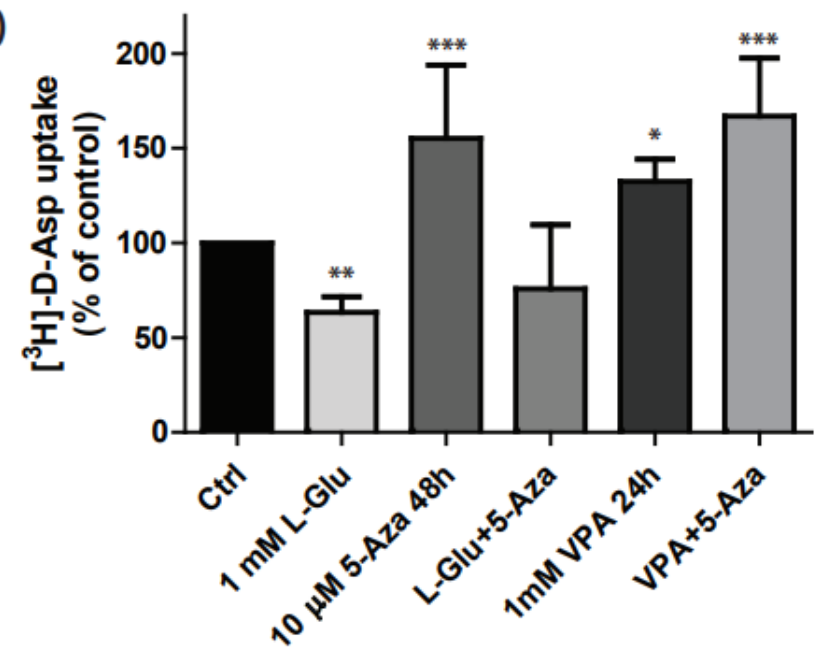

B)
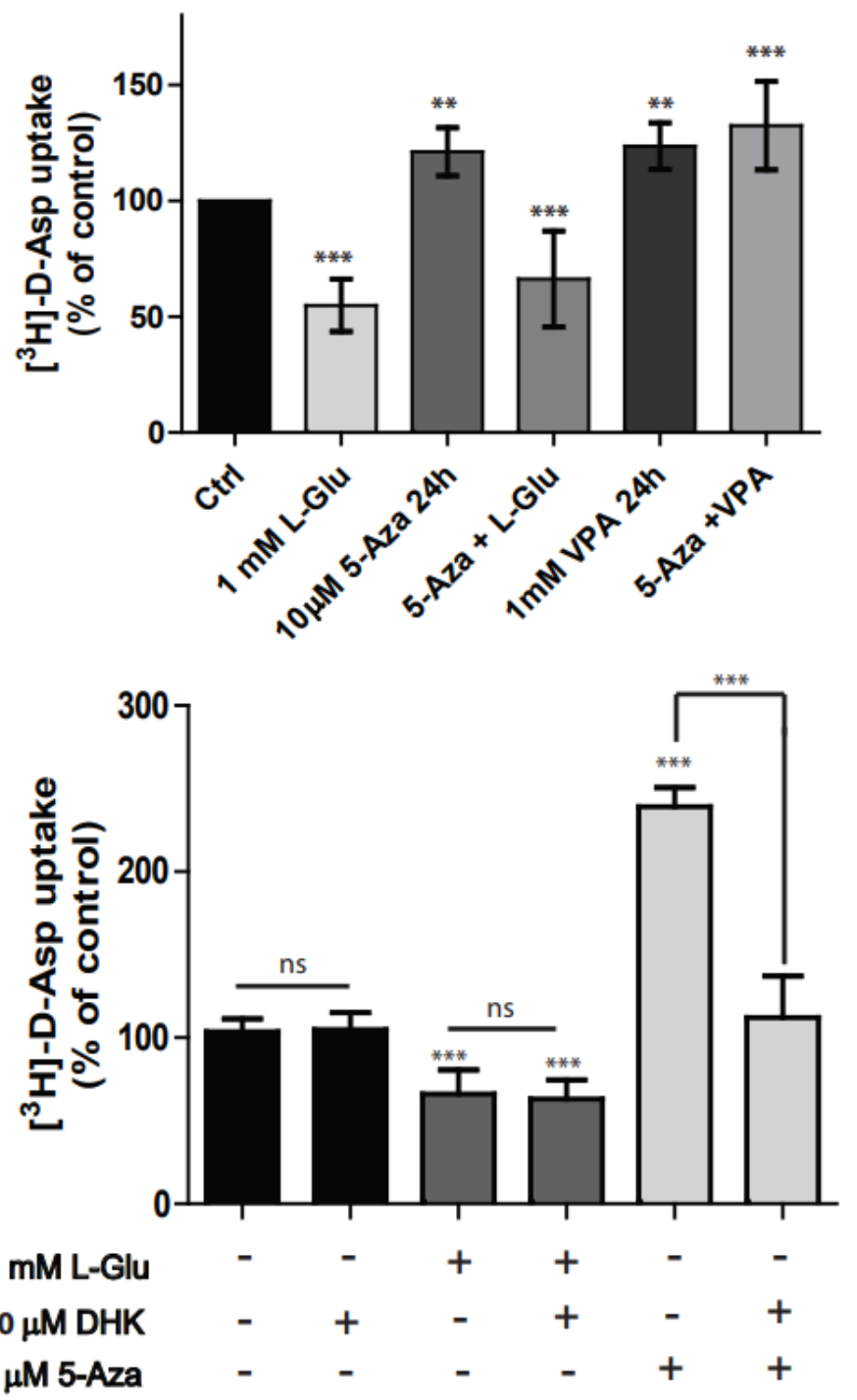

Figure 7

Glutamate transporters activity evaluation under a hypomethylating condition on MIO-M1 cell line. In order to establish the correspondent uptake activity percentage due to GLAST/EAAT1 or GLT1/EAAT2 in MIO-M1 cells we use the EAAT2 (GLT-1)-selective non-transportable inhibitor, dihydrokainic acid (DHK, 100 $\mu \mathrm{M}), \mathrm{L}-$ Glu and D-Asp in a 30 min uptake, resulting in a slight decrease in uptake activity in this cells that might be due GLT1 (A). B) and C) are the same treatment conditions differing in 5-Aza temporality treatment (24h and 48h, respectively): Ctrl, $1 \mathrm{mM} \mathrm{L-Glu} 30 \mathrm{~min}, 10 \mu \mathrm{M}$ 5-Aza, $1 \mathrm{mM}$ VPA, plus the combined effect of 5-Aza $24 \mathrm{~h}$ or $48 \mathrm{~h}$ pre-treatment followed by $1 \mathrm{mM} \mathrm{L-Glu} 30 \mathrm{~min}$ or $1 \mathrm{mM}$ VPA $24 \mathrm{~h}$. Then, cells treated with 5-Aza-2'-deoxycytidine (5-Aza) during $24 \mathrm{~h}$ increase considerably their uptake while 5-Aza treated cells combined with a 30 min final treatment with DHK had a surprisingly decrease in [3H]-D-Asp. (D). Results of three independent experiments in quadruplicate. Bars represent means \pm SD analyzed by one-way ANOVA with Dunnett's multiple comparison, ${ }^{*} P<0.01$, ${ }^{\star *} P<0.001$ and ${ }^{*} * * 00.0001$. In (B) we compared all treatments with Bonferroni's multiple comparison where ${ }^{\star \star *} \mathrm{P} \otimes 0.0001$ and ${ }^{*} \mathrm{p}<0.001$. 